\title{
Evaluation of Hydration Status, Sodium and Fluid Intake in Children with Sickle Cell Anaemia
}

Ruth Williams-Hooker*, Jane Hankins, Karen Ringwald-Smith, Michelle Stockton, Teresa A Shurley

Clinical Nutrition Services, St. Jude Children's Research Hospital, Memphis, USA

\begin{abstract}
Sickle cell anemia (SCA) is an inherited condition of chronic hemolytic anemia that includes several different genotypes. People with SCA are encouraged to drink extra fluids in order to prevent dehydration that may lead to red cell sickling and consequently more serious problems. Proper hydration is an important factor in maintaining homeostasis in the body; it is necessary to regulate body temperature, maintain energy levels, aid digestion and eliminate toxins.
\end{abstract}

Keywords: Sickle cell anemia; Sickling

\section{Introduction}

In an adequately hydrated person, overall total body water (TBW) accounts for $55-65 \%$ of overall body weight [1]. Poor hydration increases the thickness or viscosity of blood. Even mild dehydration can have an impact on hem concentration [1]. In SCA, dehydration can occur for a number of reasons, including but not limited to diarrhea, severe vomiting, excessive sweating, high atmospheric humidity and temperatures, cold temperatures, or inadequate fluid intake [2]. Furthermore, hyposthenuria (inability to concentrate urine resulting in urine of low specific gravity) is a product of tubular damage, and is present after $6-12$ months of age, and becomes progressively worse with age [3-5]. Hypothenuria compounds the risk for dehydration in patients with SCA. When patients with SCA take in too little fluid and too much sodium, this may force water from the red cells and dehydrate the cell, thus the concentration of sickle hemoglobin increases in the red cell. This increase in sickle hemoglobin can lead to pain crisis.

A study conducted at St. Jude Children's Research Hospital looked at a relationship between dietary intake of water and sodium in patients with SCA [6]. Researchers found water intake was significantly lower than adequate while sodium intake was significantly higher than sodium upper limit. An additional benefit of hydration was noted in a study by Beyer and Simmons who found when sickle cell patients increased fluid intake as a comfort measure, venous occlusive crisis (VOC) was decreased [7].

There is a deficit in the amount of information regarding hydration status in patients with SCA. In addition, the role of that both dietary water and sodium play in the incidence of VOC and pain crisis in children with SCA is not fully understood. To date, few studies have shown a clear relationship between fluid intake and total body water in SCA. Additional research could help determine if proper hydration may prove to be a simple treatment option, or an adjuvant of other antisickling therapies. This knowledge could help nutritionists develop diet plans that have a proper balance of all nutrients including water, which may help to minimize the risk of pain crisis. The purpose of this pilot study was to measure the hydration status utilizing bioelectrical impedance analysis in children with SCA and to determine if sodium and fluid intake were associated with hydration status and pain crises.

\section{Methods}

\section{Subjects}

Children with sickle cell anemia (Hgb SS or Hb S $\beta 0$-thalassemia genotypes) being treated by a pediatric Sickle Cell Program in Memphis, TN were recruited. The subject's physician discussed the study with them, reviewing the pros/cons of the study. Subjects were willing to participate and signed informed consent (and assent if older than 5 years). Inclusion criteria for enrollment were; patients with SCA (HbSS or $\mathrm{HbS} \beta^{0}$-thalassemia), between the ages of 5 to 17 years, who had the ability to lie still for up to five minutes and the ability to fast for 12 hours prior to the measurement of total body water analysis. Subjects were excluded if were using diuretics or other medications that could alter hydration status. Subjects were asked to provide details of food and fluid intake for the 24 hours prior to the measurement of TBW, and details on pain crisis, hospitalizations or use of pain medicine 2 weeks prior and 2 weeks after the TBW analysis. The study was approved by the Institutional Review Board of the University of Memphis and all research was conducted at The University of Memphis Human Performance Lab.

\section{Total body water analysis}

Bioelectrical Impedence (BIA) was performed on all subjects to access TBW [8]. Subjects were measured without their right shoe and sock, lying supine, with both arm 30 degrees from the body and legs not touching. Jewelry was also removed before conducting the analysis. The right hand and foot were cleaned with alcohol before electrodes were positioned. Subjects lay still while the analyzer was turned on and the test was conducted, which took about 3 minutes. After completion, the electrodes were removed and discarded. Data needed to calculate TBW (i.e. age, weight, height, resistance, and reactance) was entered into RJL Systems Body Composition Program, Version 2.1.

\section{Nutrient analysis}

A 24 hour food and fluid recall was obtained by the study investigator to assess sodium and fluid intake [9]. The quantity and time of day the food was consumed, and the name brand of the food if convenience

*Corresponding author: Ruth Williams-Hooker, Clinical Nutrition Services, St. Jude Children's Research Hospital, 262 Danny Thomas Place, Memphis, TN 38105-3678, USA, Tel: 901-678-3108; E-mail: mrwillia@memphis.edu

Received May 07, 2013; Accepted June 27, 2013; Published June 30, 2013

Citation: Williams-Hooker R (2013) Evaluation of Hydration Status, Sodium and Fluid Intake in Children with Sickle Cell Anaemia. J Blood Disorders Transf 4:143. doi:10.4172/2155-9864.1000143

Copyright: (c) 2013 Williams-Hooker R. This is an open-access article distributed under the terms of the Creative Commons Attribution License, which permits unrestricted use, distribution, and reproduction in any medium, provided the original author and source are credited. 
or processed was obtained. Fluid and sodium amounts were analyzed using ESHA Food Processor Diet Analyzer (2006) and compared to the United States Department of Agriculture (USDA) Dietary Reference Intake (DRI) for children ages 5 to 17 [10]. Not included in the analysis was sodium added to the food through the use of salt or seasonings by the subject before consumption.

\section{Weather analysis}

All studies were performed before 9:00 am in an effort to not prolong the fasting period. At the time BIA was conducted, the temperature and humidity was obtained and recorded from the National Weather Service website (weather.gov) specific for the zip code at The University of Memphis. BIA was performed before 9 AM in the months of July and August. The mean temperature at the time of the study was 84.7 degrees \pm 3.9 degrees. The mean humidity was $62.8 \% \pm 10.8$ percentage points.

\section{Pain crisis analysis}

Subjects and legal guardians were asked to record all painful events, hospitalizations and use of any pain medication by the subject within 2 weeks prior of the BIA examination. A follow-up phone call was made to subjects and/or legal guardians to ascertain any painful events, hospitalizations and use of pain medication by the subjects 2 weeks after the BIA examination.

\section{Data analyses}

Statistical analyses were performed using SPSS version 20 for Windows (SPSS Inc., Chicago, IL, USA). The $t$ test for independent variables was used to compare the single measurements between genders. The independent variables were subject total body water, total body water average for children 5 to 17 , subject sodium intake, Recommended Dietary Index for sodium intake, subject fluid intake, and fluid requirements per the Holliday Segar equation [11]. The significance testing and reported $p$ values were two-sided for all variables. $p$ less than 0.05 were considered statistically significant.

\section{Results}

\section{Patient demographics/Pain evaluation}

Ten subjects (all with HbSS) were included in the study; seven were females and three males, and their mean age was 11.3 years. None of the subjects reported painful events, hospitalizations nor use of any pain medication within 2 weeks prior of the BIA examination or 2 weeks after the BIA examination.

\section{Total body water (TBW)}

The mean TBW (Table 1) for the 10 subjects was 21.82 liters \pm 5.6 liters, with a minimum of 14.4 liters and a maximum of 28.7 liters TBW. The mean reference range for total body water among males and females without SCA between the ages of 5 to 17 years is 38.1 liters and 30 liters, respectively [11]. The mean TBW for males in this study was 24.73 liters, a 13.4 liter TBW deficit or $65 \%$ of the mean TBW of same age male children without SCA. The mean TBW for females in this study was 20.57 liters, a 9.4 liter TBW deficit or $69 \%$ of the mean TBW of same age female children without sickle cell anemia.

\section{Daily fluid intake}

Daily Fluid intake (Table 2) mean was 51.1 ounces \pm 23.3 ounces, with a minimum intake of 24 ounces and a maximum intake of 90 fluid ounces. Males consumed a mean of 54.33 ounces fluid while females consumed 49.71 ounces of fluid $(p=0.792)$.

\begin{tabular}{|c|c|c|c|c|c|c|}
\hline Subject & Gender & $\begin{array}{c}\text { Age } \\
\text { (years) }\end{array}$ & $\begin{array}{c}\text { TBW SCA } \\
\text { Subjects (L) }\end{array}$ & $\begin{array}{c}\text { Mean TBW } \\
\text { non-SCA (L) }\end{array}$ & $\begin{array}{c}\text { Difference } \\
\text { (L) }\end{array}$ & $\begin{array}{c}\text { Std Dev } \\
\text { (L) }\end{array}$ \\
\hline 1001 & M & 9 & 22.6 & 38.1 & 15.5 & 10.96 \\
\hline 1002 & F & 6 & 14.4 & 30.0 & 15.6 & 11.03 \\
\hline 1003 & F & 7 & 15.9 & 30.0 & 14.1 & 9.97 \\
\hline 1004 & F & 17 & 28.7 & 30.0 & 1.3 & .919 \\
\hline 1005 & M & 13 & 26.0 & 38.1 & 12.1 & 8.56 \\
\hline 1006 & F & 12 & 24.7 & 30.0 & 5.3 & 3.75 \\
\hline 1007 & F & 10 & 15.0 & 30.0 & 15.0 & 10.6 \\
\hline 1008 & M & 13 & 25.6 & 38.1 & 12.5 & 8.84 \\
\hline 1009 & F & 17 & 28.0 & 30.0 & 2.0 & 1.41 \\
\hline 1010 & F & 9 & 17.6 & 30.0 & 12.4 & 8.77 \\
\hline
\end{tabular}

${ }^{*}$ RJL Systems BIA analysis

Table 1: Total body water (TBW) of pediatric sickle cell anemia subjects versus pediatric non-sickle cell anemia of same age group.

\begin{tabular}{|c|c|c|c|c|c|c|}
\hline Subject & Gender & Age & $\begin{array}{c}\text { Fluid } \\
\text { Intake (oz) }\end{array}$ & $\begin{array}{c}\text { Recommended } \\
\text { Fluid Intake (oz) }\end{array}$ & $\begin{array}{c}\text { Difference } \\
\text { (oz) }\end{array}$ & Std Dev \\
\hline 1001 & M & 9 & 90 & 61 & 29 (over) & 20.5 \\
\hline 1002 & F & 6 & 38 & 51 & 13 & 9.19 \\
\hline 1003 & F & 7 & 88 & 53 & 35 (over) & 24.7 \\
\hline 1004 & F & 17 & 24 & 74 & 50 & 35.4 \\
\hline 1005 & M & 13 & 31 & 68 & 37 & 26.1 \\
\hline 1006 & F & 12 & 60 & 66 & 6 & 4.24 \\
\hline 1007 & F & 10 & 44 & 60 & 16 & 11.3 \\
\hline 1008 & M & 13 & 42 & 75 & 33 & 23.3 \\
\hline 1009 & F & 17 & 32 & 72 & 40 & 28.3 \\
\hline 1010 & F & 9 & 62 & 57 & 5 (over) & 3.54 \\
\hline
\end{tabular}

*First $20 \mathrm{~kg}=1500 \mathrm{ml}+20 \mathrm{ml}$ per kg over first $20 \mathrm{~kg}$

Table 2: Fluid intake of pediatric sickle cell anemia subjects versus pediatric recommendations using the Holliday-Segar method.

The average weight for males and females was $40.5 \mathrm{~kg}$ and $39 \mathrm{~kg}$, respectively. Reference value for baseline fluid requirements in normal children, of the same age group as our study patients, is $1500 \mathrm{ml}$ for the first $20 \mathrm{~kg}$ plus $20 \mathrm{ml} / \mathrm{kg}$ for each $\mathrm{kg}$ over $20 \mathrm{~kg}$ [11]. Using the average weight, baseline fluid requirement for the male group was $1910 \mathrm{ml}$ (64.6 ounces) and the baseline fluid requirement for the female group was $1880 \mathrm{ml}$ (63.6 ounces). The mean fluid intake of the male group was 54.33 ounces fluid while females consumed 49.71 ounces of fluid, both considerably lower than fluid requirements.

\section{Daily sodium intake}

Daily Sodium intake (Table 3) mean was 2.4 grams \pm 0.9 grams, with a minimum intake of 1 gram and a maximum intake of 3.9 grams sodium. This recorded sodium intake did not account for sodium added while cooking or before consumption.

Mean sodium intake per day in the male group was 2.7 grams. The mean sodium intake per day in the female group was 2.3 grams with non significance of $p=0.511$.

The USDA dietary reference intake of sodium per day for children between the ages of 5 and 17 is 1.2 to 1.5 grams a day. The mean average of sodium intake per day for the male group was 2.7 grams (225\% above recommended). The mean sodium intake in the female group was 2.3 grams (190\% above recommended).

\section{Discussion}

Vaso-occlusive crisis in sickle cell disease can be triggered by low hydration status and weather changes [12]. There are several ways to 


\begin{tabular}{|c|c|c|c|c|c|c|}
\hline Subject & Gender & Age & $\begin{array}{c}\text { Sodium } \\
\text { Intake (gm) }\end{array}$ & $\begin{array}{c}\text { DRI Sodium } \\
\text { (gm)+ }\end{array}$ & $\begin{array}{c}\text { Difference } \\
\text { (gm) }\end{array}$ & Std Dev \\
\hline 1001 & M & 9 & 3.9 & 1.5 & 2.4 & 1.70 \\
\hline 1002 & F & 6 & 2.5 & 1.2 & 1.3 & 0.92 \\
\hline 1003 & F & 7 & 1.1 & 1.2 & -0.1 & 0.07 \\
\hline 1004 & F & 17 & 1.3 & 1.5 & -0.2 & 0.14 \\
\hline 1005 & M & 13 & 1.9 & 1.5 & 0.4 & 0.28 \\
\hline 1006 & F & 12 & 3.3 & 1.5 & 1.8 & 1.27 \\
\hline 1007 & F & 10 & 3.3 & 1.5 & 1.8 & 1.27 \\
\hline 1008 & M & 13 & 2.3 & 1.5 & 0.8 & 0.57 \\
\hline 1009 & F & 17 & 1.9 & 1.5 & 0.4 & 0.28 \\
\hline 1010 & F & 9 & 2.4 & 1.2 & 1.2 & 0.85 \\
\hline
\end{tabular}

+USDA Dietary Reference Intake

Table 3: Sodium intake of pediatric sickle cell anemia subjects versus pediatric dietary reference intake.

test TBW, including laboratory based tests and predication equations. Predication equations are based on various calculations taking into consideration maturation, ethnic background or specific medical conditions [8]. BIA is inexpensive, rapid, can be conducted in various locations including hospital bedside or in a clinic and noninvasive [13]. In a population, where hydration status may have an impact on pain crisis, BIA may be a viable way to access fluid.

BIA results in our study show these children had a deficit of TBW by a mean of 10.6 liters when compared to reference range values for age-matched non-SCA children. Poor hydration increases the viscosity of the blood and can impact hem concentration resulting in VOC [14]. However, our subjects did not report any pain 2 weeks prior to or after the BIA measurement. It could be that dehydration affects TBW and pain crisis, much longer out that this research study reported, or that our sample size was too small to see any meaningful difference.

Dietary intervention to limit sodium and increase fluid intake may be necessary in pediatric sickle cell patients. Dietary recall in this study showed not only was fluid intake below recommended levels and sodium levels were above dietary recommendations, also the fluid becoming consumed was high in sodium content (sodas, and electrolyte-containing beverages). An earlier study conducted at St. Jude Children's Research Hospital that looked at the relationship between dietary intake and sodium in patients with SCA [6]. This study confirms information reported in that study, and complements our study by showing that TBW is low in this group of patients with SCA.

A study conducted by The University of Minnesota, found 24 hour recall to be a valid method for assessing dietary recall in children as young as 8 years of age [9]. The 24 hour recall conducted in this study could not account for sodium added during cooking or added before consumption.

Weather can contribute to hydration status which can possibly affect pain crisis. In a study addressing temperature changes and extremes related to emergency visits and hospitalizations for sickle cell crisis done by Smith et al. [15] it was determined that temperatures $<32^{\circ} \mathrm{F}$ and $>80^{\circ}$ Fahrenheit had positive correlations with hospital admissions that were statistically and clinically significant. Another study which looked at weather and hospital admissions for pain crisis conducted concluded that high wind speeds and low humidity contribute to an increased number of pain crisis hospital admissions. High wind speed and low humidity may also be associated with increased fluid loss through sweating [16].

Contrary to lower than average TBW, high sodium intake and low fluid intake, none of the subjects presented with pain crisis, hospitalizations or use of medications two weeks prior and two weeks after the BIA. This result is contrary to the information found by Vichinsky and Lubin that found that low hydration status is a common factor leading to pain crisis in SCA [12].

\section{Limitations}

Limitations include having a convenience sample, limited sample size, using 24 hour recall to assess dietary intake, and the short study period. Having a limited sample size may not have given enough data to accurately assess pain crisis, hospitalization and use of pain medication in relation to low total body water, fluid intake, sodium intake and weather changes. Using 24 hour food recall may not accurately represent actual dietary intake since it is based on a person's recollection of what food and beverage was consumed, not taking into account preparation or items that may be forgotten during the recall. As stated earlier, recorded sodium intake is lower than actual based on inability to account for added sodium during cooking or before consumption. A study period of 2 summer months could not account for humidity or temperature changes below 32 degrees or higher than the recorded mean of 84.7 degrees. Future studies may benefit from a higher number of participants, a longer research/study period, and monitoring sodium and fluid intake in both a control and test group while also using a 3-day food record completed by the participants. Finally, this study was conducted during 2 summer months, with average temperature of greater than 80 degrees Fahrenheit, which could have exacerbated insensible water loss, and decreased TBW content, and urine specific gravity was not measured in this group.

\section{Conclusion}

The hallmark complication of sickle cell disease is VOC associated with hematological changes. Maintaining adequate fluid status may aid in the prevention of blood viscosity increases, which precipitates the obstruction of blood flow leading to pain crisis [7]. In this study we have shown that children with SCA consume higher than recommended sodium-rich foods (such as chips, snack foods and processed foods), and lower than recommended fluid intake, resulting in a lower than expected TBW content for age. Additional research still needs to be done to determine whether TBW, sodium and fluid intake, and humidity and temperature changes are associated with increased VOC pain crisis in children with SCA. Finally, kidney abnormalities, such as albuminuria and renal insufficiency, are common complications in individuals with SCA, and a common cause of death among adults [17,18]. Adding information about renal function to future studies examining the role of hydration in SCA will help the understanding of the contributions of adequate sodium consumption and maintenance of appropriate TBW to disease complications and disease severity.

\section{References}

1. Berne R, Levy M (1988) Physiology. (2ndedn). St Louis: CV Mosby Company.

2. Redding-Lallinger R, Knoll C (2006) Sickle cell disease--pathophysiology and treatment. Curr Probl Pediatr Adolesc Health Care 36: 346-376.

3. ITANO HA, KEITEL HG, THOMPSON D (1956) Hyposthenuria in sickle cel anemia: a reversible renal defect. J Clin Invest 35: 998-1007.

4. PERILLIE PE, EPSTEIN FH (1963) Sickling phenomenon produced by hypertonic solutions: a possible explanation for the hyposthenuria of sicklemia. J Clin Invest 42: 570-580.

5. Francis YF, Worthen HG (1968) Hyposthenuria in sickle cell disease. J Nat Med Assoc 60: 266-270. 
Citation: Williams-Hooker R (2013) Evaluation of Hydration Status, Sodium and Fluid Intake in Children with Sickle Cell Anaemia. J Blood Disorders Transf 4:143. doi:10.4172/2155-9864.1000143

6. Fowler KT, Williams R, Mitchell CO, Levy MC, Pope LF, et al. (2010) Dietary water and sodium intake of children and adolescents with sickle cell anemia. $J$ Pediatr Hematol Oncol 32: 350-353.

7. Beyer JE, Simmons LE (2004) Home treatment of pain for children and adolescents with sickle cell disease. Pain Manag Nurs 5: 126-135.

8. Horlick M, Arpadi SM, Bethel J, Wang J, Moye J Jr, et al. (2002) Bioelectrical impedance analysis models for prediction of total body water and fat-free mass in healthy and HIV-infected children and adolescents. Am J Clin Nutr 76: 991999

9. Lytle LA, Nichaman MZ, Obarzanek E, Glovsky E, Montgomery D, et al. (1993) Validation of 24-hour recalls assisted by food records in third-grade children. The CATCH Collaborative Group. J Am Diet Assoc 93: 1431-1436.

10. Dietary Reference Intakes. Assessed at http://fnic.nal.usda.gov/dietaryguidance/dietary-reference-intakes. May 7, 2013.

11. Gunn V, Nechyba C (2002) Harriet Lane Handbook, 16th ed. Philadelphia, PA: Mosby 234-235.

12. Vichinsky EP, Lubin BH (1980) Sickle cell anemia and related hemoglobinopathies. Pediatr Clin North Am 27: 429-447.
13. Shanholtzer BA, Patterson SM (2003) Use of bioelectrical impedance in hydration status assessment: reliability of a new tool in psychophysiology research. Int J Psychophysiol 49: 217-226.

14. Rogovik AL, Persaud J, Friedman JN, Kirby MA, Goldman RD (2011) Pediatric vasoocclusive crisis and weather conditions. J Emerg Med 41: 559-565.

15. Smith WR, Coyne P, Smith VS, Mercier B (2004) Temperature changes, temperature extremes, and their relationship to emergency department visits and hospitalizations for sickle cell crisis. Pain Manag Nurs 4: 106-111.

16. Jones S, Duncan ER, Thomas N, Walters J, Dick MC et al. (2005) Windy weather and low humidity are associated with an increased number of hospital admissions for acute pain and sickle cell disease in an urban environment with a maritime temperate climate. $\mathrm{Br} \mathrm{J}$ Haematol 131: 530-533.

17. Aygun B, Mortier NA, Smeltzer MP, Hankins JS, Ware RE (2011) Glomerula hyperfiltration and albuminuria in children with sickle cell anemia. Pediatr Nephrol 26: 1285-1290.

18. Powars DR, Chan LS, Hiti A, Ramicone E, Johnson C (2005) Outcome of sickle cell anemia: a 4-decade observational study of 1056 patients. Medicine (Baltimore) 84: 363-376. 